\title{
ESTIMAÇÃO DE PARÂMETROS DA EQUAÇÃO PENG- ROBINSON PARA O BIODIESEL ATRAVÉS DE VALORES DE MASSA ESPECÍFICA EM FUNÇÃO DA TEMPERATURA
}

\author{
R. M. CAVALCANTE ${ }^{1}$, S. P. de MAGALHÃES ${ }^{2}$, R. S. STEIN ${ }^{1,2}$, E. S. FIGUEIREDO ${ }^{2}$, S. \\ M. C. da SILVA ${ }^{1}$, F. L. P. PESSOA ${ }^{1}$ \\ ${ }^{1}$ Universidade Federal do Rio de Janeiro, Escola de Química \\ ${ }^{2}$ Instituto Nacional de Tecnologia, Divisão de Energia/LACOL \\ E-mail para contato: shayane.pereira@int.gov.br
}

\begin{abstract}
RESUMO - O biodiesel é um dos principais biocombustíveis produzidos no Brasil. Atualmente, todo o diesel comercializado no território brasileiro contém $7 \%(\mathrm{v} / \mathrm{v})$ de biodiesel. O aumento do percentual na mistura deste ao óleo diesel interfere nas propriedades do combustível podendo afetar a performance do motor e as emissões de gases de combustão. O conhecimento de propriedades fluidodinâmicas como viscosidade e massa específica é importante por influírem na circulação e injeção do combustível. Para o biodiesel, esses valores variam de acordo com a matéria-prima utilizada em sua síntese. Entretanto, é possível prever essas propriedades, em função da temperatura e pressão, através do uso de equações de estado e o conhecimento de suas propriedades críticas. Neste contexto, o objetivo deste trabalho é estimar os parâmetros da equação de estado cúbica de Peng-Robinson (PR) a fim de predizer a massa específica do biodiesel. O modelo termodinâmico foi capaz de prever os valores de massa específica do biodiesel em função da temperatura com desvios absoluto pequenos $(<0,3 \%)$.
\end{abstract}

\section{INTRODUÇÃO}

O biodiesel é um combustível derivado de fonte renovável que reduz a emissão de alguns gases poluentes, como o dióxido de carbono (Van Gerpen, 2005). A biomassa é uma importante fonte renovável de energia, podendo ser utilizada como combustível de forma direta ou indireta. O etanol e o biodiesel são exemplos de biocombustíveis obtidos através da conversão de biomassa a partir de diferentes processos como pirólise, hidrólise ácida, esterificação, entre outros (Magalhães, 2010).

A adição de biodiesel ao óleo diesel ajuda na redução da emissão de gases causadores do efeito estufa. O Conselho Nacional de Política Energética (CNPE) estabeleceu que, a partir de $1^{\circ}$ de novembro de 2014, todo o óleo diesel comercializado no Brasil deve conter $7 \%$ (em volume) de biodiesel, ou seja, passou a ser obrigatória a utilização da mistura B7 em motores diesel (ANP, 2014).

A transesterificação é um dos processos mais utilizados na produção do biodiesel. Esta consiste na reação de um triglicerídeo (presentes nos óleos e gorduras) com um álcool de cadeia curta, obtendo-se uma mistura de ésteres de ácidos graxos (biodiesel) e glicerina 
(principal subproduto). A reação acontece normalmente na presença de um catalisador, sendo a rota alcalina a principal tecnologia utilizada em escala industrial.

Para garantir que o biodiesel possa ser utilizado sem causar danos aos motores a diesel é essencial que se conheçam as propriedades físicas, químicas e termodinâmicas do biocombustível. Algumas destas propriedades são de difícil medição e, portanto, são pouco encontradas na literatura (Cavalcante, 2010). A massa específica, por exemplo, é uma importante propriedade a ser conhecida, pois afeta diretamente a performance do motor e a emissão de gases. Um combustível com alto valor de massa específica pode fazer com que haja liberação de fumaça negra e de material particulado (Alptekin e Canakci, 2008).

A medida experimental da massa específica em função da temperatura é de grande utilidade na construção de modelos termodinâmicos. Estes são capazes de predizer diferentes propriedades termodinâmicas e o equilíbrio de fases de sistemas como o da mistura ternária álcool + biodiesel + glicerol, necessário para o projeto e otimização de reatores e de separadores utilizados na síntese de biodiesel (Cavalcante, 2010).

O objetivo deste trabalho é, portanto, empregar a equação de estado cúbica de PengRobinson para predizer a massa específica do biodiesel metílico de soja comparando os resultados com valores obtidos experimentalmente.

\section{METODOLOGIA EXPERIMENTAL}

As amostras de biodiesel metílico de soja foram fornecidas pelo Laboratório de Tecnologia Verdes (GreenTec) da EQ/UFRJ. As medidas de densidade, em intervalo de temperatura de $288 \mathrm{~K}$ a $363 \mathrm{~K}$, foram realizadas utilizando um densímetro digital Anton Paar modelo DMA 4500 segundo a norma ASTM D 4052:2011. As medidas foram feitas em triplicatas.

\section{MODELAGEM TERMODINÂMICA}

Com a intenção de poder representar o comportamento PVT (Pressão-VolumeTemperatura) do líquido e do vapor de biodiesel em uma larga faixa de temperatura e pressão, utilizou-se a equação de estado cúbica de Peng-Robinson (EEC-PR) para a predição da massa específica do biodiesel.

A Equação 1 mostra a EEC de Peng-Robinson explícita em termo de pressão. A equação possui um termo de atração $(a)$ dependente de temperatura e do fator acêntrico (Smith et al., 2007). Esta equação pode também ser expressa em termos do fator de compressibilidade $(Z)$ conforme mostra a Equação 2.

$$
\begin{aligned}
& P=\frac{R T}{V-b}-\frac{a(T)}{(V-\varepsilon b)(V+\sigma b)} \\
& Z=\frac{1}{1-b \rho}-\frac{a}{\rho R T\left(\frac{1}{\rho^{2}}+\frac{2 b}{\rho}-\frac{1}{b^{2}}\right)}
\end{aligned}
$$


onde $P$ é a pressão total do sistema; $R$ é constante universal dos gases; $T$ representa a temperatura; $V$ é o volume molar; $\varepsilon$ e $\sigma$ são parâmetros da EEC-PR com valores tabelados; os coeficientes $a$ e $b$ são dependentes das propriedades críticas da substância, e podem ser calculados através das Equações 3 e 4, respectivamente.

$$
\begin{aligned}
& a(T)=0,45724 \cdot \alpha\left(T_{r}\right) \frac{\left(R T_{c}\right)^{2}}{P_{c}} \\
& b=0,0778 \frac{R T_{c}}{P_{c}}
\end{aligned}
$$

onde $T_{c}$ e $P_{c}$ são, respectivamente, a temperatura e a pressão crítica do componente puro; $\alpha\left(T_{r}, \omega\right)$ é a função de dependência do parâmetro $a$ com a temperatura e com o fator acêntrico calculada através da Equação 5.

$$
\alpha\left(T_{r}, \omega\right)=\left[1+\left(0,37464+1,54226 \omega-0,26992 \omega^{2}\right)\left(1-T_{r}^{1 / 2}\right)\right]
$$

onde $\omega$ representa o fator acêntrico; $T_{r}$ é a temperatura reduzida.

Para muitas substâncias, os valores das propriedades críticas $\left(T_{c}, P_{c}\right)$ são obtidos experimentalmente, entretanto, para o biodiesel, esses valores devem ser estimados, uma vez que o mesmo sofre degradação térmica a partir de $523 \mathrm{~K}$ (West et al., 2008; Magalhães, 2014). O fator acêntrico representa a não-esfericidade da molécula e é um parâmetro dependente das propriedades críticas da substância (Reid et al., 1987). Portanto, o cálculo da massa específica do biodiesel através da EEC-PR requer que este parâmetro seja estimado.

Neste trabalho, os valores de $T_{c}, P_{c}$ foram estimados minimizando-se a função objetivo dos mínimos quadrados (Equação 6) em ambiente Matlab. A rotina fminsearch existente no programa foi adotada como ferramenta de minimização. Esta utiliza o método de otimização não linear (Nelder-Mead Simplex).

$$
F O=\sum_{i}\left(\rho_{\text {calc }, i}-\rho_{\text {exp }, i}\right)^{2}
$$

onde $F O$ é a função a ser minimizada, variando-se os parâmetros a serem estimados; $\rho_{\text {calc, } i}$ é a massa específica do biodiesel calculado através da EEC-PR na temperatura $i ; \rho_{\text {exp }, i}$ é a massa específica do biodiesel na temperatura $i$ obtida experimentalmente.

O termo que engloba o fator acêntrico $\left(0,37464+1,5422 \omega-0,26992 \omega^{2}\right)$ presente na Equação 5 foi substituído por um parâmetro, aqui chamado de $f(\omega)$. Este parâmetro foi estimado juntamente com as propriedades críticas $\left(T_{c}, P_{c}\right)$. componente.

O biodiesel (mistura de ésteres metílicos) foi considerado como um pseudo- 


\section{RESULTADOS E DISCUSSÃO}

Os dados experimentais (valores médios das triplicatas) de massa específica em função da temperatura medidos a pressão atmosférica (1 atm) e os valores ajustados através do modelo termodinâmico EEC-PR são mostrados na Figura 1. Os parâmetros estimados e o desvio absoluto (Equação 7) são apresentados na Tabela 1.

$$
D A(\%)=\sum_{i=0}^{n o b s}\left(\frac{\left|\rho_{\text {calc }, i}-\rho_{\text {exp }, i}\right|}{n o b s}\right) * 100
$$

onde $D A$ é o desvio absoluto; nobs é o número de observações experimentais feitas.

Figura 1 - Comportamento experimental da massa específica biodiesel metílico de soja em função da temperatura e comparação com os valores preditos através da EEC-PR.

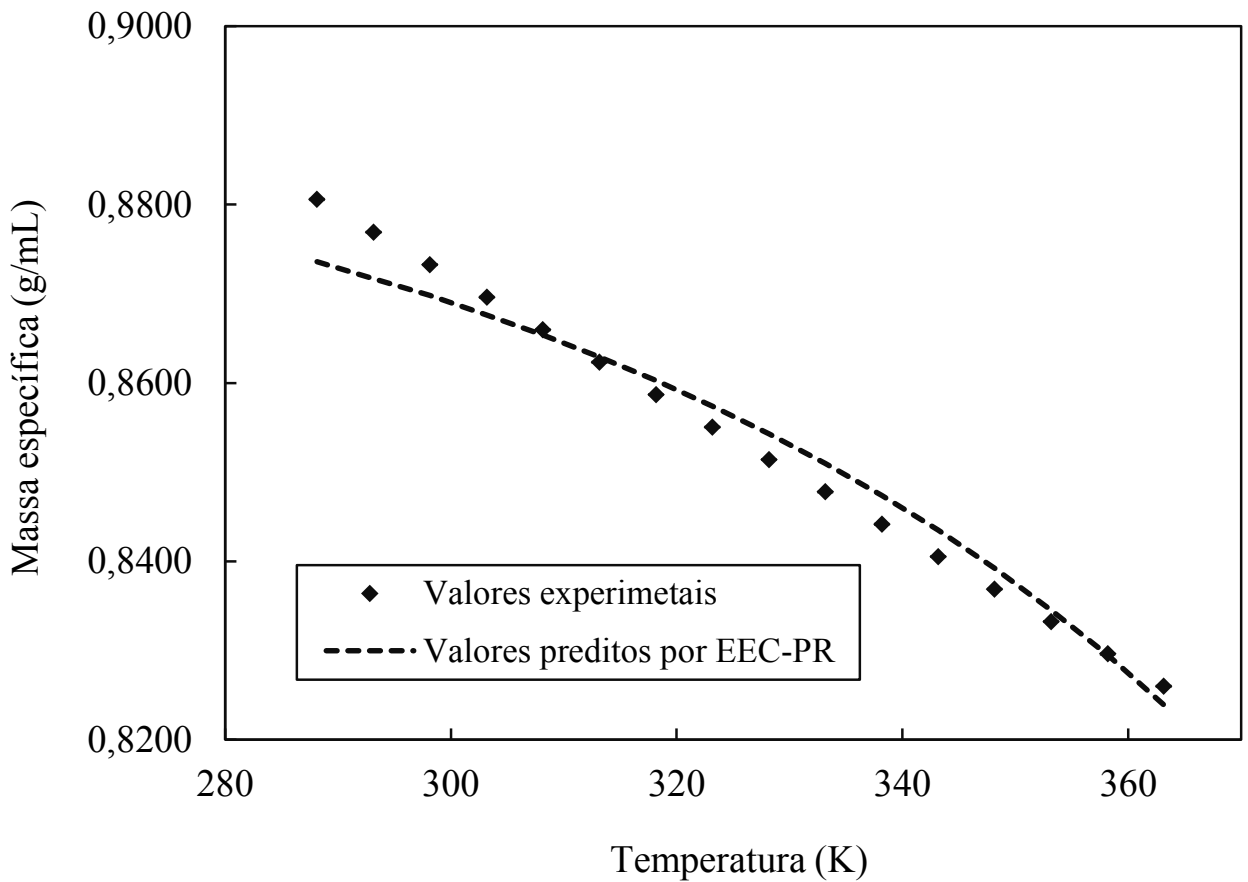

Tabela 1 - Valores ajustados das propriedades críticas e função do fator acêntrico para o biodiesel metílico de soja.

\begin{tabular}{cccc}
\hline $\mathrm{T}_{\mathrm{c}}(\mathrm{K})$ & $\mathrm{P}_{\mathrm{c}}(\mathrm{kPa})$ & $F(\omega)$ & $\% D A(g / m L)$ \\
\hline 698,92 & 1393,820 & $-8,9107$ & 0,26 \\
\hline
\end{tabular}

Os resultados obtidos mostraram que a equação de estado cúbica de Peng-Robinson foi capaz de descrever o comportamento dos dados experimentais de forma satisfatória, apresentando desvios pequenos em relação aos mesmos. Isso mostra que, na ausência de dados experimentais, a metodologia proposta pode ser utilizada como alternativa para a 
predição da densidade do biodiesel, lembrando apenas que, como os valores das constantes críticas não podem ser verificados experimentalmente, os valores obtidos são apenas parâmetros ajustados aos dados experimentais.

\section{CONCLUSÃO}

Os resultados da modelagem termodinâmica apresentaram desvios menores que $0,3 \%$ em relação aos valores experimentais. Dessa forma, a metodologia proposta, na qual foi feito o ajuste das propriedades críticas e de uma função do fator acêntrico, mostrou ser uma boa alternativa na predição da massa específica do biodiesel utilizando a equação de estado cúbica de Peng-Robinson.

\section{NOMENCLATURA}

$\begin{array}{ll}a & \text { Parâmetro da equação de Peng-Robinson, }(\mathrm{a}=1+\sqrt{2}) \\ b & \text { Parâmetro da equação de Peng-Robinson, }(\mathrm{b}=1-\sqrt{2}) \\ D A & \text { Desvio absoluto }\end{array}$

EEC-PR Equação de estado cúbica de Peng-Robinson

$\begin{array}{ll}f(w) & \text { função do fator acêntrico } \\ n o b s & \text { Número de observações experimentais } \\ P & \text { Pressão do sistema, } \mathrm{Pa} \\ P_{c} & \text { Pressão crítica, } \mathrm{Pa} \\ R & \text { Constante universal dos gases perfeitos, } \mathrm{m}^{3} \cdot \mathrm{Pa} / \mathrm{K} \cdot \mathrm{mol} \\ T & \text { Temperatura, } \mathrm{K} \\ T_{c} & \text { Temperatura crítica, } \mathrm{K} \\ T_{r} & \text { Temperatura reduzida, } \mathrm{T} / \mathrm{T}_{\mathrm{c}} \\ V & \text { Volume molar, } \mathrm{m}^{3} / \mathrm{mol}\end{array}$

Letras gregas

$\alpha\left(T_{r}\right) \quad$ Função de dependência do parâmetro $a$ com a temperatura

$\varepsilon \quad$ Parâmetro tabelado da equação de estado cúbica de Peng-Robinson

$\rho \quad$ Massa específica $(\mathrm{g} / \mathrm{mL})$

$\rho_{\exp } \quad$ Massa específica experimental $(\mathrm{g} / \mathrm{mL})$ 


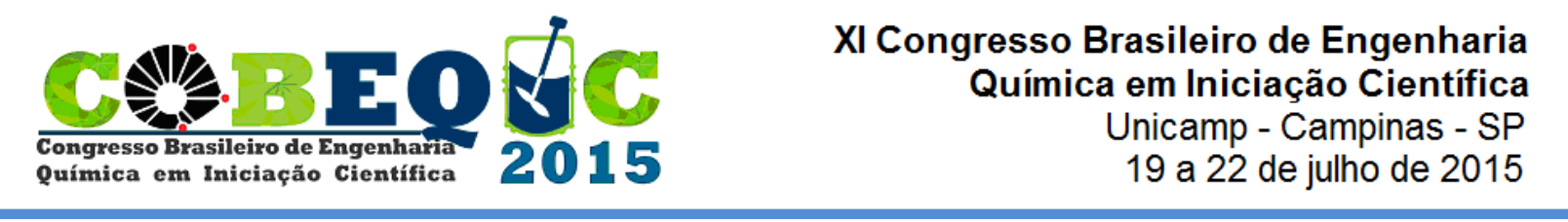
$\rho_{\text {calc }} \quad$ Massa específica calculada $(\mathrm{g} / \mathrm{mL})$
$\sigma \quad$ Parâmetro tabelado da equação de estado cúbica de Peng-Robinson
$\omega \quad$ Fator acêntrico

\section{REFERÊNCIAS}

ANP - Agência Nacional do Petróleo, Gás Natural e Biocombustíveis. Biocombustíveis: Biodiesel. Disponível em: $<$ http://www.anp.gov.br/>. Acesso em 03 de março de 2015.

ALPTEKIN, E., CANAKCI, M. Determination of the density and the viscosities of biodiesel- diesel fuel blends. Renewable Energy, v. 33, p. 2623-2630, 2008.

CAVAlCANTE, R. M., Predição da densidade de biodiesel proveniente de diferentes matérias-primas. Dissertação (Mestrado em Ciências)-Programa de Pós-Graduação em Tecnologia de Processos Químicos e Bioquímicos, Escola de Química, Universidade Federal do Rio de Janeiro, Rio de Janeiro, 2010.

MAGALHÃES, S. P. de, Estudo de modelos cinéticos para a reação de transesterificação enzimática de óleos vegetais. Dissertação (Mestrado em Ciências)-Programa de PósGraduação em Tecnologia de Processos Químicos e Bioquímicos, Escola de Química, Universidade Federal do Rio de Janeiro, Rio de Janeiro, 2010.

MAGALHÃES, S. P. de, Estudo de modelos cinéticos para a reação de transesterificação enzimática de óleos vegetais. Tese (Doutorado em Ciências)-Programa de PósGraduação em Engenharia Química, COPPE, Universidade Federal do Rio de Janeiro, Rio de Janeiro, 2014.

REID, R. C., PRAUSNITZ, J. M., POLING, B. E., The properties of gases and liquids. $4^{\mathrm{a}}$ ed., McGraw Hill, Inc, New York, p.656-732, 1987.

SMITH, J. M., VAN NESS, H. C., ABBOTT, M. M. Introdução à termodinâmica da engenharia química. $7^{\text {a }}$ Edição. LTC, Rio de Janeiro, 2007.

VAN GERPEN, J., Biodiesel processing and production. Fuel Processing Technology, 86, p. 1097-1107, 2005.

WEST, A. H., POSARAC, D., ELLIS, N., Assessment of four biodiesel production processes using HYSYS.Plant. Bioresource Technology, 14, p. 6587-6601, 2008. 